\title{
SPEECH BY PROFESSOR G. C. WAKE FOR THE PROFESSOR B. F. GRAY DINNER
}

Colleagues, I have been given this awesome task of presenting this tribute to Brian. This is a daunting task and I think both Brian and I are terrified! Myself, because of it being such a privilege to be asked to do such a formidable task, and Brian I guess because of what I might say! Yes, Brian, I have got all the evidence! I hereby open the case. I've asked many people lately for views of the Brian we know well-the consensus is "a good bloke"-perhaps I could leave it at that. No! This meeting of course says a lot. We are here to salute a colleague who, by his intellect, scholarship and dedicated efforts has contributed an enormous amount internationally to our understanding of quantum chemistry (his first area), branching chain reactions, muscle modelling, spontaneous ignition (with the theory and experimental aspects) and mathematical chemistry generally. All of us here, Brian, and many others worldwide, congratulate you for your contributions and thank you for the leadership you've shown in the subjects mentioned above.

The written form of this tribute will contain a lot more biographical information on Brian Frederick Gray. Briefly here, he took his PhD at the University of Manchester in 1957 in quantum chemistry under the supervision of Huw Pritchard, now in York University, Toronto. Our conference proceedings contain a nice anecdote about that time from Huw and I urge you to read it. I'll return to this later.

Brian then held a series of posts which clearly all contributed to his powerful development

1957-58 Fulbright Scholar and A. A. Noyes Fellow at Caltech with Linus Pauling

1958-59 Research Fellow in Theoretical Chemistry at University of Keele, UK with Professor McWeeny

1959-62 Lecturer in Theoretical Chemistry at University of Salford, UK

1962 Senior Physicist, General Dynamics/Astronautics, San Diego, California

1962-67 Theoretical Physics Group, General Research Corporation at Santa Barbara with Lippman and Harry Yang

1967-76 Reader in Mathematical Chemistry, School of Chemistry, University of Leeds

1977-98 Professor of Chemistry, Macquarie University, Sydney, Australia

1991-95 Foundation ARC Senior Fellow, University of Sydney

1998-onwards Entrepreneur par excellence.

A glance at the conference volume, eventually to be the substance of a special issue of The ANZIAM Journal, shows the enormity of what he has contributed. It is an incredible career. Inevitably, Andy McIntosh's comments from the Leeds fraternity 
remind those of us here of how we came to know Brian and his work. For the Australian fraternity it is of course when he first came here to the Chair of Chemistry at Macquarie in 1977 determined to give Chemistry new impetus in research and a more rigorous approach. Macquarie, as I recall from visits in the 1970's and 1980's, never quite knew what hit it and he must have caused many to cringe as he battled to give Macquarie the edge he wanted. He has been a member of ANZIAM for over a decade and is a "regular" at the February meetings. We look forward to his contributions to future meetings.

His research output is impressive and is continuing into an active "retirement". There are to date 190 papers, with a total of 61 co-authors-of which I have the honour to be the one who occurs in that glorious list the most! I think Brian has the same relationship to me in my lesser list of publications (thus I have Gray number $=1$, see postscript)! There is a long list of PhD students and research fellows. I know 2 well-Clifford Jones (UK) and Rowena Ball (Australia). And now to the total figure of Brian .... .

I am probably, with Professor John Brindley from Leeds, the person here who has known Brian longest. Let me share some anecdotes with you. I first met Brian in December 1970 at Leeds, where as a postdoctoral fellow at Oxford, I was flattered by his namesake and mentor, Peter Gray, the senior guru of combustion at Leeds at that time, inviting me and my beloved family to visit Leeds to speak and meet the strong Leeds fraternity. I spoke on the topic of shape factors in spontaneous ignition and the concept of bounding spheres. I was of course behaving like the proverbial Kiwi who couldn't fly and was very nervous. Brian was noticeable for his probing questions and he took the opportunity of talking at length with me during this very exciting visit.

I became then part of the extended Leeds fraternity and inevitably I spent my next sabbatical from New Zealand at the University of Leeds in 1976-77 arranged again by Professor Peter Gray, who intended that I should strengthen the links between chemistry and mathematics there.

I seem destined to be always "seeing Brian off". What next? In December 1976 while I was in Leeds, Brian and Anne took off for the distant state of Australia. Their farewell, which I attended, was a riotous affair (like this) and I knew that when I returned to Kiwiland later in 1977, Brian and I would become linked across the Tasman in our mutual interest in the mathematical theory of thermal ignition.

As a person trained in mathematics I thought my role was to keep Brian's unbounded enthusiasm for the use of mathematics in chemical kinetics and heat-transfer on the straight and narrow. I'll let history judge whether or not I succeeded. But I did try. He now knows a lot about $\frac{d x}{d t}$ !!

Of course the little story in Huw Pritchard's contribution shows Brian was always an uncontainable unconventional researcher, capable of enormous breakthroughs with an amazing disregard of conventional mathematical thinking. We visited each other 
often on both sides of the Tasman Sea. I, with others, was able to provide Brian with access to the methods of nonlinear systems which he now uses with ease and with great success. He became a key figure in Australian Applied Mathematics and was rewarded with a Senior Australian Research Fellowship in the inaugural round of 1991.

Here we are "sending Brian off" from his paid professional life! This occasion is his retirement from the University full-time position. But he'll be with us for a long time yet stretching us to the limit as he always does.

Brian is unconventional in life as a whole as well as in his research. I have a lot of anecdotes. He has a great nose for deals. One research worker was deployed to the state of Victoria so Brian could register his fleet of Jaguars there rather than NSW so as to save money.

There is a nice list of sayings about things you can "learn from your dog". Can I share a couple with you that clearly apply to Brian:

Never pass up the opportunity to go for a joy-ride.

Let others know when they have invaded your territory.

Take naps often and stretch before rising.

Eat with gusto and enthusiasm.

If what you want lies buried, dig until you find it.

Avoid biting when a simple growl will do.

On hot days, drink lots of liquid and lie under a shady tree.

I must stop. Brian we wish you and Anne the best for the future and look forward to your continuing involvement in the subject of Applied Mathematics par BFG par excellence.

11th February 1999

GRAEME WAKE

Professor of Applied Mathematics

University of Canterbury

Postscript: At the post ANZIAM99 meeting on combustion, the 20 participants revealed the following statistics:

- Average Gray number: 1.8 (= number of "the sequence of in-common authors to reach B. F. Gray")

- \# who had Gray number $=1$ was 10 , with 47 papers recorded

- Average number of years they have known B. F. Gray $=9 \frac{1}{2}$ years. 